\title{
Effect of Different Workscope Strategies on Wind Turbine Gearbox Life Cycle Repair Costs
}

\author{
A. Lesmerises ${ }^{1}$, and D. Crowley ${ }^{2}$ \\ ${ }^{1,2}$ StandardAero Engineering Services, 3523 General Hudnell Dr., San Antonio, TX, USA 78226 \\ Alan.Lesmerises@StandardAero.com \\ David.Crowley@StandardAero.com
}

\begin{abstract}
The wind turbine industry is beginning to establish orthodoxies governing the repair of gearboxes, including policies governing the replacement of bearings during gearbox heavy maintenance events. Some maintainers recommend replacing all of the bearings, every time, regardless of condition or age. At the same time, others prefer to only replace the failed bearing. The former rationale achieves availability by spending more money than absolutely necessary; the latter sacrifices reliability in exchange for a lower shop visit cost. Even though neither approach results in the lowest Life Cycle Cost, no standard practice has yet been implemented to methodically determine what would be the best approach. Furthermore, as gearboxes approach the end of their planned service lives, a different strategy may be called-for. This paper presents an illustrative example of using a reliability-based statistical analysis to determine which strategy will yield the lowest Life Cycle Cost for wind turbine gearboxes.
\end{abstract}

\section{INTRODUCTION}

Many Wind Turbine asset owners have been faced with the question of whether to reuse or replace bearings while a wind turbine gearbox is undergoing heavy maintenance. Some owners believe that only bearings with extensive damage should be replaced (commonly referred to as "OnCondition" Maintenance or OCM), while others prefer to proactively replace all bearings to avoid unplanned failures. The difference in shop visit costs associated with these two strategies can be significant; shop visit costs can be less than $\$ 10 \mathrm{~K}$ (when using a condition-based approach) to over $\$ 100 \mathrm{~K}$ (material cost to replace all bearings).

Lesmerises, et al. This is an open-access article distributed under the terms of the Creative Commons Attribution 3.0 United States License, which permits unrestricted use, distribution, and reproduction in any medium, provided the original author and source are credited.
From a reliability standpoint, bearings present a rather complex problem. Standard life expectancies for bearings are typically stated as " $\mathrm{L}_{10}$ " (or $\mathrm{B}_{10}$ ) lives. They represent the total service time by which $10 \%$ of a population of bearings can be expected to fail. However, their actual service lives can vary significantly depending on the design of the system they're used in, their duty cycle, and the condition of the lubrication system used to support them.

The Aviation and Gas Turbine industries have developed clear definitions for inspection and reuse of bearings used on aircraft and in powerplants. These industries typically follow a "condition-based" approach. If the bearings meet defined acceptance criteria, they are reused regardless of the economics involved or time in service. In providing these services, StandardAero complements these condition assessments with economic evaluations that relate the estimated remaining useful life to the cost of parts being replaced and the life expectancy of the unit being repaired (based on which parts will be replaced), enabling the asset owner to realize a lower long-term cost per service hour.

Just as it is for wind turbine asset owners, maintainers of many other types of complex rotating equipment face the same fundamental question of whether to repair only what is broken (an OCM strategy) and potentially live with short service lives until the next maintenance event, or should parts be refurbished or replaced every time regardless of condition (a pure overhaul strategy), potentially incurring costs without extending time in service or receiving the full benefit from the increased costs.

Answering this dilemma requires a clear methodology to determine when one strategy or another is more economical. The goal of this paper is to lay out the foundation for determining when it is more economical to proactively replace the bearings versus an "inspect and reuse" approach when a gearbox is undergoing heavy maintenance. A new SAE Aerospace Recommended Practice, JA6097 - Using a System Reliability Model to Optimize Maintenance Costs, 
A Best Practices Guide (2013) describes one such methodology that can be applied to virtually any type of system, including wind turbine gearboxes. This methodology can be explained by walking the reader through an analysis of both the OCM and pure overhaul strategies, and then comparing those results with an even more optimal maintenance approach.

One significant drawback of maintenance approaches based on a single policy for all assets (such as the pure OCM or pure overhaul approaches) is that they don't take into consideration that each asset comes in for maintenance in a different "state". The particular components installed in the system frequently have different service histories, and hence make different reliability contributions to the system's future performance. This is especially significant when it comes to complex, heavily integrated repairable systems what constitutes the "best" decisions to be made at each shop visit will be different based on the state of each asset. The principal advantage of the approach described in JA6097 is that it simultaneously addresses both the cost and reliability impact of various corrective maintenance actions being considered at a given shop visit, a major shortcoming of many other optimization techniques (Wang, 2002).

\section{AsSumptions ANd Cost Data}

For this analysis, we wanted to consider as many costs that an asset owner will incur over the lifetime of a gearbox as possible. There may be other costs not shown here, and some of these costs will vary based on location, the make and model of units involved, source of supply, and economies of scale.

We realize that some operators may disagree with some of the particular values assumed below. At the same time, we also had to protect the confidentiality of data provided to us by other wind turbine operators. However, for the purposes of this analysis, the following costs were judged sufficient to provide a reasonable assessment and comparison. More importantly, it will still illustrate an objective data-driven methodology for determining which maintenance strategy is more cost effective. In practice, values derived from the individual asset owner's actual equipment and experiences would be used for these computations.

The following assumptions and costs used for this study:

\begin{tabular}{rrl}
\hline Operating Hours/Yr & 3,000 & Hrs * \\
\hline Total Hrs over 20 Yrs & 60,000 & Hrs \\
\hline Total Hrs over 25 Yrs & 75,000 & Hrs \\
\hline
\end{tabular}

Table 1. Gearbox Usage

* - An approximate value reported by some wind turbine operators. While this may be representative in general, individual operators can and do experience significant seasonal variations due to geographic location (weather, topography, etc.).

\begin{tabular}{rrl}
\hline Crane to RR Gearbox & $\$ 60,000$ & per event \\
\hline $\begin{array}{r}\text { RR Gearbox } \\
\text { days/2 techs }\end{array}$ & 48 & Hrs Labor \\
\hline Shipping (in and back) & $\$ 6,000$ & per event \\
\hline Misc. Material & $\$ 4,000$ & per event \\
\hline Avg. cost/bearing & $\$ 8,000$ & ea \\
\hline Qty Bearings/Gearbox & 14 & ea \\
\hline Field Labor Costs & $\$ 100$ & $/ \mathrm{Hr}$ \\
\hline Shop Labor Costs & $\$ 100$ & $/ \mathrm{Hr}$ \\
\hline Gearbox Major Repair & 450 & $\mathrm{Hrs}$ Labor \\
\hline Gearbox Med Repair & 350 & $\mathrm{Hrs}$ Labor \\
\hline Gearbox Minor Repair & 350 & $\mathrm{Hrs}$ Labor \\
\hline Revenue & $\$ 0.06$ & $/ \mathrm{KWH}$ \\
\hline
\end{tabular}

Table 2. Costs and labor per event

\begin{tabular}{rr}
\hline Crane & $\$ 60,000$ \\
\hline Labor to RR Gearbox & $\$ 4,800$ \\
\hline Lost Sales (1 week) & $\$ 5,000$ \\
\hline Shipping & $\$ 6,000$ \\
\hline Shop Repair Cost & $\$ 47,000$ \\
\hline Total & $\$ 122,800$ \\
\hline
\end{tabular}

Table 3. Costs to replace 1 bearing off-tower

These also assume that there will be one (1) crane visit for each gearbox remove \& replace (RR) event, and that a serviceable gearbox will always be available.

\begin{tabular}{rr}
\hline Crane & $\$ 60,000$ \\
\hline Labor to RR Gearbox & $\$ 4,800$ \\
\hline Lost Sales (1 Week) & $\$ 5,000$ \\
\hline Shipping & $\$ 6,000$ \\
\hline Shop Repair Cost & $\$ 157,000$ \\
\hline Total & $\$ 232,800$ \\
\hline
\end{tabular}

Table 4. Costs to replace all bearings off-tower

\subsection{Expected Lives for Wind Turbine Bearings}

Currently, there is limited data on the times to failure for gearbox bearings. However, for the purposes of this analysis, we used the minimum required $\mathrm{L}_{10}$ lives specified by ANSI/AGMA/AWEA 6006-A03, Standard for Design and Specification of Gearboxes for Wind Turbines (2003).

These standard values represent life expectancies, without regard for the particular equipment in which they're installed, usage rates, environmental conditions (such as weather), and other factors that can affect bearing life. In fact, feedback from the Wind Turbine industry indicates that actual service lives do vary significantly from the $\mathrm{L}_{10}$ values given in the standard. However, lacking specific data from 
actual units in service, we assumed they represent a reasonable assessment of likely bearing lives that were sufficient for this study.

\begin{tabular}{|c|c|c|}
\hline Gearbox Size & 1500 & KW \\
\hline \multirow{2}{*}{ Total Availability } & $3000 \mathrm{hrs} / \mathrm{yr}$ & \multirow{2}{*}{$=34 \%$} \\
\hline & $365 \times 24 \mathrm{hrs} / \mathrm{yr}$ & \\
\hline Average Revenue & $\$ 0.06$ & / KWH \\
\hline $\begin{array}{l}\text { Average Revenue } \\
\text { @ 34\% Availability }\end{array}$ & $\$ 734$ & / day \\
\hline $\begin{array}{l}\text { Maximum Revenue } \\
\text { @ 100\% Availability }\end{array}$ & $\$ 2,160$ & / day \\
\hline Lost Sales Rate & $\$ 1,000$ & / day \\
\hline Lost time/Gearbox failure & 5 & days \\
\hline Average Revenue @ 34\% & $\$ 268,056$ & $/ \mathrm{yr}$ \\
\hline KWH per Yr & $4,467,600$ & \\
\hline KWH over 20 Yrs & $89,352,000$ & \\
\hline KWH over 25 Yrs & $111,690,000$ & \\
\hline Typical Site & 100 & Turbines \\
\hline $\begin{array}{l}\text { Revenue per Site } \\
\text { @ 34\% Availability }\end{array}$ & $\$ 26,805,600$ & / yr \\
\hline
\end{tabular}

Table 5. Opportunity Costs

To perform our analysis, this data was converted to equivalent Weibull Parameters using an assumed slope of 3.43 (heavy wear out). This value was chosen based on StandardAero's experience with similar equipment. While some believe a Lognormal distribution would be more appropriate for bearings, our experience overhauling aerospace gearboxes indicates that the bearings and gears are very effective at transferring debris to one another and actual failures tends to exhibit more of a wear-out behavior. The value of the Weibull slope can vary significantly depending on the system design, applied loads, and other factors. As with the cost data above, actual bearing failure history data would need to be used to determine the true bearing service characteristics (in terms of the Weibull slope and characteristic life, or equivalent if another statistical distribution was more appropriate).

To convert the values above to equivalent Weibull parameters, start with the Cumulative Distribution Function (CDF):

$$
F(t)=1-e^{-(t / \eta)^{\beta}}
$$

By rearranging the terms to solve for $\eta$, we get

$$
\eta=\frac{t}{[-\ln (1-F(t))]^{1 / \beta}}
$$

where $\beta=3.43, \mathrm{~F}(\mathrm{t})=0.10\left(10 \%\right.$ for the $\mathrm{L}_{10}$ life), and $\mathrm{t}$ is the $\mathrm{L}_{10}$ life (in hours) value taken from the AGMA Standard
(2003), listed below. The equivalent Weibull parameters for

\begin{tabular}{|c|c|c|c|}
\hline Bearing Position & $\begin{array}{c}\mathbf{L}_{10} \text { Life } \\
\text { (Hrs) }\end{array}$ & $\begin{array}{c}\text { Charac- } \\
\text { teristic } \\
\text { Life } \\
(\text { Eta, } \eta)\end{array}$ & $\begin{array}{c}\text { Slope } \\
(\text { Beta, } \boldsymbol{\beta})\end{array}$ \\
\hline High Speed Shaft & 30,000 & 57,816 & 3.43 \\
\hline Intermed. Speed Shaft & 40,000 & 77,089 & 3.43 \\
\hline Low Speed Shaft & 80,000 & 154,178 & 3.43 \\
\hline Planet Carrier & 100,000 & 192,723 & 3.43 \\
\hline Planet Gears & 100,000 & 192,723 & 3.43 \\
\hline
\end{tabular}
the applicable $\mathrm{L}_{10}$ Lives are given in Table 6.

Table $6 . \mathrm{L}_{10}$ ratings and equivalent Weibull Parameters

\section{ANALYSIS AND RESUltS}

For this study, two types of analysis were carried out. For the first analysis, we built a reliability model to determine event occurrence rates for each of the strategies of interest. The $2^{\text {nd }}$ analysis looked at the life cycle impact at specific points along the planned life.

In this case, since the failure of any single component in the gearbox would render the entire system unserviceable, a simple series reliability model was used. The overall system reliability was computed as follows:

$$
R_{s}(t)=\prod_{i}^{n} R_{i}\left(t \mid t_{i 0}\right)
$$

where the system ' $s$ ' consists of a set of ' $n$ ' components, and time-continued components would contribute a conditional reliability based on any operating time accumulated to-date $\left(t_{i 0}\right)$. New or restored components use a $t_{i 0}$ value of zero for their reliability contribution.

\subsection{Reliability Model - OCM vs. $100 \%$ Replacement}

Using the minimum bearing lives from AGMA 6006-A03 (2003), a system level reliability model was created for a typical gearbox (bearings only). The model was constructed using Raptor reliability modeling software. The resulting reliability model was analyzed under two scenarios.

1. All bearings replaced when any one bearing fails

2. Only the failed bearing is removed and replaced. Other bearings are allowed to continue in service

The results showed that if all bearings are replaced at each visit, the Mean Time Between Failure (MTBF) of the gearbox would be 37,691 hours. Over a planned 20 year life, this would result in 1.6 expected events per gearbox, and 1.9 expected events occurring over a 25 years life.

However if only the failed bearings were removed and replaced (the OCM strategy), the subsequent MTBF would drop to 8,096 hours. This would result in 3.8 events over 20 
years, and 4.6 events over 25 years.

Based on the assumed cost of each event, the 20 year life cycle cost for replacing all bearings at each heavy maintenance event appears to be less than replacing only the failed bearings (the same would also be true over a 25 year life cycle). A summary of the results is provided below.

\subsection{Cost Benefit Summary}

$\begin{aligned} & \text { Replace All } \\
& \text { Bearings 100\% }\end{aligned}$
\begin{tabular}{|l|r|c|c|}
\hline Events over 20 yrs & 1.59 & & \\
\hline Events over 25 yrs & 1.99 & & \\
\hline Cost per event & $\$ 232,800$ & & \\
\hline Total Cost 20 Yrs & $\$ 370,592$ & $\$ 6.18$ & $\$ 0.00415$ \\
\hline Total Cost 25 Yrs & $\$ 463,241$ & $\$ 6.18$ & $\$ 0.00415$ \\
\hline
\end{tabular}

Table 7. Costs for a "Replace $100 \%$ " strategy

$\begin{aligned} & \text { Replace Only Failed } \\
& \text { Bearing \& Continue }\end{aligned}$
\begin{tabular}{|l|r|r|l|}
\hline Events over 20 yrs & 3.76 & & \\
Hr of Use & \multicolumn{1}{c|}{ KWH } \\
\hline Events over 25 yrs & 5.61 & & \\
\hline Cost per event & $\$ 122,800$ & & \\
\hline Total Cost 20 Yrs & $\$ 461,183$ & $\$ 7.69$ & $\$ 0.00516$ \\
\hline Total Cost 25 Yrs & $\$ 688,702$ & $\$ 9.18$ & $\$ 0.00617$ \\
\hline
\end{tabular}

Table 8. Costs for an OCM strategy

$\begin{aligned} & \text { Replace 100\% vs. } \\
& \text { Only Failed Bearing }\end{aligned}$
\begin{tabular}{|l|r|c|c|}
\hline Helta @ 20 Yrs & $\$ 90,590$ & $\$ 1.51$ & $\$ 0.00101$ \\
\hline Delta @ 25 Yrs & $\$ 225,462$ & $\$ 3.01$ & $\$ 0.00202$ \\
\hline
\end{tabular}

Table 9. Comparison of replacement strategies

\subsection{Workscope Cost Impacts at Different Points in a Gearbox's Life}

While reviewing the data for the analysis above, we noted that many failures are likely to occur late in a unit's planned life. Under a "replace $100 \%$ strategy", these units would receive a workscope that restored its reliability past the unit's planned service life. Based on this, we thought it important to look at how the economics of the replacement strategy change along the unit's life.

To perform this analysis, a simplified gearbox reliability model was constructed including only the gearbox bearings. By integrating the system reliability function in Eq. (3), we can determine the system life expectancy $E(T)$ after repair based on any previously accumulated operating times (if any) of individual bearings installed in that gearbox.

$$
E_{s}(T)=\int_{0}^{\infty} \prod_{i}^{n} R_{i}\left(t \mid t_{i 0}\right) d t
$$

The parameters for the minimum bearing lives (shown above) were used to calculate the system life expectancy after each repair over the planned 20 (or 25) year lives of the gearboxes, for the following four scenarios:

(1) Replacing only the failed bearing

(2) Replacing all bearings

(3) Replacing only the minimum number of bearings to reach a planned life

(4) Replacing only the HSS and ISS bearings (the least reliable bearings)

Using the assumed cost data given above, the resulting life expectancy was divided into the workscope cost, and the results were output in terms of the expected Cost per Hour of Reliable Life (Cost/Hr) from the build. The results of this are summarized in Table 10 and shown graphically in Figure 1 and Figure 2 below.

Based on these results, the lowest cost strategy falls under either Scenario 3 or 4 where only a few select bearings are replaced. While the "Replace $100 \%$ " strategy tended to have a lower LCC cost after 9-12 years (when compared to the OCM strategy), neither were better than a strategy that continually evaluated the optimum build over the unit's life.

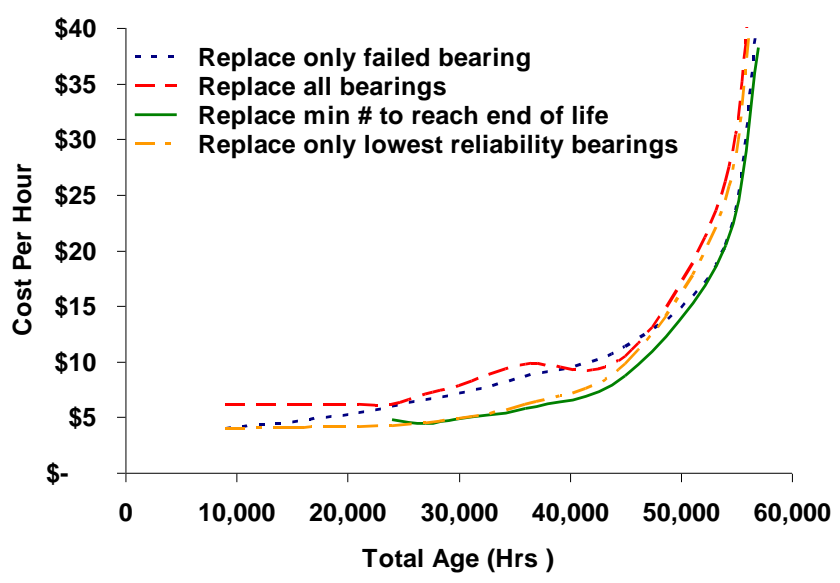

Figure 1. Cost Per Hour of Use (20 Yr Planned Life)

The cost spread between the least to best strategy ranged from approximately $\$ 2$ per hour (for gearboxes workscoped in the $1^{\text {st }} 10$ years of its life), to more than $\$ 10$ an hour (for gearboxes workscoped in the last 10 years of its life). The resulting savings from using the optimum strategy is approximate $\$ 100,000$ (over the planned life) or $\$ .001 / \mathrm{KWH}$ (\$ $2 / \mathrm{hr}$ over last 50,000 hours, or $\$ 10 / \mathrm{Hr}$ over last 10,000 hours). 


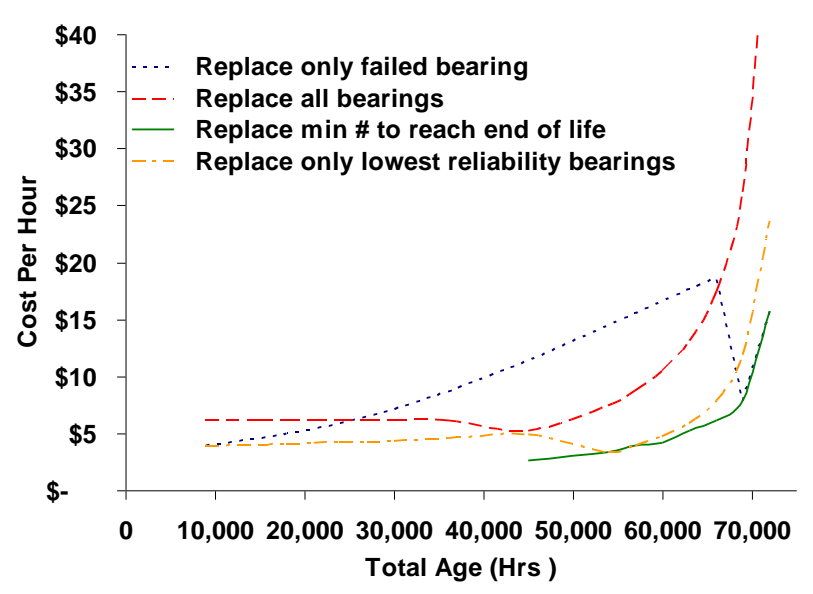

Figure 2. Cost Per Hour of Use (25 Yr Planned Life)

\section{DISCUSSION}

Based on the analysis above, the optimum workscope depends upon the age of the unit, the accumulated operating time and reliability of its sub-assemblies, and the planned life of the unit.

It should also be noted that only 4 workscopes were considered. If the replacement or re-use of each bearing is considered a different workscope, then there are potentially $2^{14}(16,384)$ workscopes, one for each possible combination of replacing or re-using any of the 14 bearings in the gearbox. This complexity (i.e., number of workscopes) will increase significantly as gears and other major components are included in the optimum cost analysis. Because of this, the example discussed here only partially answers the question of the optimum workscope for a given gearbox at a given point in time. In reality, a customized software tool would be needed to evaluate all the other permutations of possible workscopes.

The analysis performed used a very generic reliability model. In reality, each of the primary failure modes (for all components, not just bearings) that could cause a gearbox to be removed from service should be included such a model. For many gas turbine engines repaired by StandardAero, we do use a more complete reliability model that accounts for the effect of 50 to 100 distinct failure modes (and the corresponding statistical failure distributions), as part of a software tool that optimizes the workscope for each engine. This allows us to make much more accurate assessments of the costs and relative benefits of different workscopes, and tailor the workscope at each shop visit.

It is also important to reiterate that this study focused on the reliability of bearings alone for the sake of simplicity, but also because this is a particular area of concern for wind power asset owners. We recognize that the root causes of bearing failures can be driven by a number of factors including the cleanliness of oil, duty cycles, the specific design, and the final manufacturing dimensions of the gearbox. Furthermore, there are other components that can and do drive gearbox removals. Therefore, a more accurate and comprehensive reliability model that includes individual failure distributions for each root cause failure mechanism would be needed to find the true optimum maintenance workscope during each gearbox shop visit.

\section{CONCLUSION}

For this study, two types of analysis were carried out.

\begin{tabular}{|c|c|c|c|c|c|c|c|c|c|c|c|}
\hline \multirow[b]{2}{*}{ Age (Yrs) } & \multirow[b]{2}{*}{$\begin{array}{c}\text { Age } \\
\text { (Total } \\
\text { Hours) } \\
\end{array}$} & \multicolumn{2}{|c|}{$\begin{array}{l}\text { Scenario 1 } \\
\text { OCM (Replace only } \\
1 \text { failed bearing) }\end{array}$} & \multicolumn{2}{|c|}{$\begin{array}{c}\text { Scenario 2 } \\
\text { Replace } 100 \% \\
\text { (all 14 bearings) }\end{array}$} & \multicolumn{4}{|c|}{$\begin{array}{l}\underline{\text { Scenario } 3} \\
\text { Replace minimum number of } \\
\text { bearings to reach planned life }\end{array}$} & \multicolumn{2}{|c|}{$\begin{array}{l}\text { Scenario } 4 \\
\text { Replace only HSS } \\
\text { and ISS bearings }\end{array}$} \\
\hline & & $\begin{array}{c}\text { Cost/Hr } \\
20 \text { yr life }\end{array}$ & $\begin{array}{c}\text { Cost/Hr } \\
25 \text { yr life }\end{array}$ & $\begin{array}{c}\text { Cost/Hr } \\
20 \text { yr life }\end{array}$ & $\begin{array}{c}\text { Cost/Hr } \\
25 \mathrm{yr} \text { life } \\
\end{array}$ & $\begin{array}{l}\text { \# Brgs to } \\
\text { Reach } \\
20 \text { yrs }\end{array}$ & $\begin{array}{c}\text { Cost/Hr } \\
20 \text { yr life }\end{array}$ & $\begin{array}{l}\text { \# Brgs to } \\
\text { Reach } \\
25 \text { yrs }\end{array}$ & $\begin{array}{c}\text { Cost/Hr } \\
25 \mathrm{yr} \text { life }\end{array}$ & $\begin{array}{c}\text { Cost/Hr } \\
20 \mathrm{yr} \text { life }\end{array}$ & $\begin{array}{c}\text { Cost/Hr } \\
25 \mathrm{yr} \text { life }\end{array}$ \\
\hline 3 & 9000 & $\$ 3.90$ & $\$ 3.90$ & $\$ 6.13$ & $\$ 6.13$ & N/A & N/A & N/A & N/A & $\$ 4.01$ & $\$ 4.01$ \\
\hline 5 & 15000 & $\$ 4.58$ & $\$ 4.58$ & $\$ 6.13$ & $\$ 6.13$ & N/A & N/A & N/A & N/A & $\$ 4.09$ & $\$ 4.09$ \\
\hline 6 & 18000 & $\$ 5.01$ & $\$ 5.01$ & $\$ 6.13$ & $\$ 6.13$ & N/A & N/A & N/A & N/A & $\$ 4.13$ & $\$ 4.13$ \\
\hline 9 & 27000 & $\$ 6.85$ & $\$ 6.85$ & $\$ 7.05$ & $\$ 6.13$ & 4 & $\$ 4.45$ & N/A & N/A & $\$ 4.51$ & $\$ 4.32$ \\
\hline 10 & 30000 & $\$ 7.68$ & $\$ 7.68$ & $\$ 7.76$ & $\$ 6.13$ & 4 & $\$ 4.89$ & N/A & N/A & $\$ 4.96$ & $\$ 4.40$ \\
\hline 12 & 36000 & $\$ 9.75$ & $\$ 9.75$ & $\$ 9.70$ & $\$ 6.13$ & 3 & $\$ 5.78$ & N/A & N/A & $\$ 6.20$ & $\$ 4.58$ \\
\hline 15 & 45000 & $\$ 14.02$ & $\$ 14.02$ & $\$ 15.52$ & $\$ 7.76$ & 2 & $\$ 8.72$ & 4 & $\$ 4.89$ & $\$ 9.92$ & $\$ 4.96$ \\
\hline 18 & 54000 & $\$ 20.47$ & $\$ 19.85$ & $\$ 38.80$ & $\$ 11.09$ & 1 & $\$ 20.47$ & 4 & $\$ 6.99$ & $\$ 24.80$ & $\$ 7.09$ \\
\hline 19 & 57000 & $\$ 40.93$ & $\$ 22.18$ & $\$ 77.60$ & $\$ 12.93$ & 0 & $\$ 35.60$ & 4 & $\$ 8.16$ & $\$ 49.60$ & $\$ 8.27$ \\
\hline 20 & 60000 & & $\$ 25.04$ & & $\$ 15.52$ & & & 4 & $\$ 9.79$ & & $\$ 9.92$ \\
\hline 21 & 63000 & & $\$ 27.37$ & & $\$ 19.40$ & & & 3 & $\$ 11.57$ & & $\$ 12.40$ \\
\hline 22 & 66000 & & $\$ 30.34$ & & $\$ 25.87$ & & & 3 & $\$ 15.42$ & & $\$ 16.53$ \\
\hline 23 & 69000 & & $\$ 36.45$ & & $\$ 38.80$ & & & 2 & $\$ 21.80$ & & $\$ 24.80$ \\
\hline 24 & 72000 & & $\$ 40.93$ & & $\$ 77.60$ & & & 1 & $\$ 40.93$ & & $\$ 49.60$ \\
\hline 25 & 75000 & & & & & & & & & & \\
\hline N/A & & lanned 1 & der any & rkscope & & & & & & & \\
\hline
\end{tabular}

Table 10. Analysis Results: Cost per hour across planned gearbox life 
The first analysis involved the construction of a system reliability model and simulating the effect of two different maintenance scenarios over planned lives of 20 and 25 years to determine the expected number of maintenance events under each strategy.

This initial analysis indicated that a strategy based on replacing all the bearings at each shop visit (Replace 100\%) would result in less than two shop visits on average over the planned service life (20 and 25 years) of a gearbox. Conversely, an OCM strategy, where only the failed bearing is replaced at each event, would result in an average of close to 4 events over the planned gearbox life. When the costs of each shop visit were considered against the number of events, the "100\% Replacement" strategy had a lower overall life cycle costs $(\$ 5.70 / \mathrm{hr}$ versus more than $\$ 7.60 / \mathrm{hr})$.

The second analysis showed the optimum workscope (as measured by a combination of the shop cost and the resulting mean time to next failure) is determined by a number of factors including (1) the age of the unit, (2) the age of the other bearings in the unit and (3) the planned retirement age of the unit. It also showed that neither the OCM nor the $100 \%$ Replacement strategy was optimum. In fact, it showed that the optimum build varied significantly over the life of a unit, and the cost impact could be as much as $\$ 15$ per hour of use, per workscope.

The conclusion from our analysis is that the optimum build can vary significantly over a unit's planned life and neither an "OCM" nor a " $100 \%$ Replacement" strategy is optimum. The cost consequences are approximately $\$ 100,000$ over the lifetime of a single unit, or $\$ .001$ per KWH.

Furthermore, asset owners need tools that can determine the optimum build throughout the service life of their equipment and, quantify the benefit in terms of cost and reliability; as well as a maintenance plan that allows them to act on the data in a manner that minimizes the asset owner's long-term costs.

\section{NOMENCLATURE}

$\beta \quad$ "Slope" (or shape parameter) of a Weibull Cumulative Distribution Function (CDF)

$\eta \quad$ "Characteristic Life" (or scale parameter) for a Weibull Cumulative Distribution Function

KWH Kilowatt-Hour

$\mathrm{L}_{10}$ life Time by which $10 \%$ of a population would be expected to have failed (also called $\mathrm{B}_{10}$ life)

LCC Life Cycle Cost

MTBF Mean Time Between Failure

OCM “On-Condition Maintenance" - a maintenance philosophy of only replacing parts that have failed

RR Remove \& Replace

\section{REFERENCES}

1. American Gear Manufacturers Association (AGMA) (2003). Standard for Design and Specification of Gearboxes for Wind Turbines. In ANSI/AGMA/AWEA 6006-A03, Alexandria, VA, American Gear Manufacturers Association.

2. Society of Automotive Engineering (SAE) (2013). Using a System Reliability Model to Optimize Maintenance Costs, A Best Practices Guide. In $S A E$ ARP JA6097 MAY2013, Warrendale, PA, Society of Automotive Engineers.

3. Wang, H. (2002). Invited Review - A survey of maintenance policies of deteriorating systems. European Journal of Operational Research, vol. 139 (2002), pp. 469-489, ISSN 0377-2217. 


\section{BIOGRAPHIES}

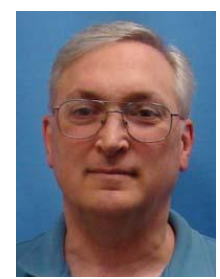

Alan Lesmerises is the lead Reliability and Life Cycle Management Engineer for StandardAero Engineering Services in San Antonio, TX. He holds a Bachelor's degree in Aerospace Engineering from the University of Oklahoma, a Master's Degree in Astronautical Engineering from the Air Force Institute of Technology (AFIT), where he completed their post-graduate Reliability and Maintainability program. During nearly 21 years in the US Air Force, he was a jet engine mechanic, performed research on gas turbine engine combustion, and was a systems engineer on various Air Force acquisition programs. Since joining StandardAero in 1999, he has supported the T56 Engine overhaul operation and is one of the original members of their Reliability Engineering team. Alan is a member of the SAE, a senior member of both the AIAA and ASQ, and an ASQ Certified Reliability Engineer. He is currently the chairman of the SAE G-11M Maintainability, Supportability, \& Logistics Committee, a member of the SAE Integrated Vehicle Health Management (IVHM) committee, and advises the SAE Aerospace Council as a member of the Integrated Vehicle Health Management Steering Group.

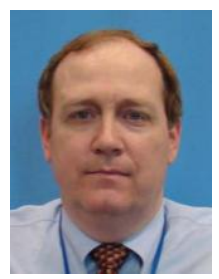

David Crowley is Director of Technology Development, StandardAero Engineering Services, San Antonio, TX. Mr. Crowley holds a Bachelor of Science Degree in Mechanical Engineering from Texas Tech University, and a Masters of Science Degree in the Management of Technology from The University of Texas at San Antonio. Prior to joining StandardAero, he worked at the US Air Force's Propulsion Directorate, San Antonio Air Logistics Center, performing various duties in support of the USAF's fleet of T56 and TF39 Engines. His last assignment was as Chief Engineer for USAF TF39 engines, where his team implemented a number of reliability improvements, costbased workscope tools, and engine modifications. David joined StandardAero in June 2000, and until Aug 2006 served as the Director of Product Engineering. In this role, he oversaw engineering support to StandardAero's T56 Engine facility, also located in San Antonio. David now leads a team to research, design, and field advancements in cost-effective aircraft propulsion systems maintenance management. 